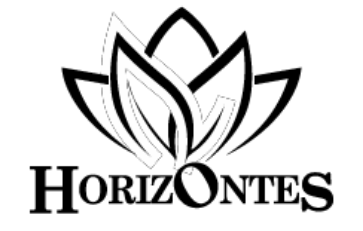

www.revistahorizontes.org
Horizontes. Revista de Investigación en Ciencias de la Educación Https://doi.org/10.33996/revistahorizontes.v4i16.104

Octubre - Diciembre 2020 Volumen 4 / No. 16

ISSN: 2616 - 7964

ISSN-L: $2616-7964$

pp. $398-414$

\title{
Ecuavóley, el rey de los deportes para los ecuatorianos en el mundo
}

\author{
Ecuavolley: The king of sports for ecuadorians in the world
}

Ecuavolley, o rei dos esportes dos equatorianos no mundo

ARTÍCULO DE INVESTIGACIÓN

\author{
Alex Galeano-Terán \\ a.galeano@alumnosek.onmicrosoft.com \\ astewran@gmail.com \\ ORCID: 0000-0003-2858-1129
}

Universidad Camilo José Cela

\author{
Paola Chuquín \\ ikitoch@hotmail.com \\ ORCID: 0000-0001-5792-5301
}

Universidad Internacional de la Rioja

Recibido 24 de agosto 2020 | Arbitrado y aceptado 23 de septiembre 2020 | Publicado en diciembre 2020

\section{RESUMEN}

Los procesos migratorios, así como las características singulares que posee el ecuavóley, han permitido una acelerada masificación dentro y fuera del Ecuador, consiguiendo un gran impacto socio-cultural. Los objetivos planteados fueron: determinar lugar y fecha del primer campeonato internacional de ecuavóley, conocer los países en los que se practica el ecuavóley, determinar el número de personas que se dan cita diariamente a ver o practicar este deporte, determinar si existe equidad de género en su práctica. En esta investigación se desarrolló una metodología mixta, basada en el paradigma cualitativo, fundamentándose a partir de sus cuatro fases científicas, preparatoria, de campo, análisis documental e informativa; iniciando con un análisis bibliográfico, para posteriormente mediante la metodología cuantitativa, tabular la información obtenida de 472 entrevistas estructuradas, mediante el programa estadístico SPSS. Obteniendo como resultado: 13 países en los que se practica ecuavóley, el primer campeonato internacional de ecuavóley se llevó a cabo en Madrid, España el 29 de abril del 2007, siendo sábado el día que más afluencia hay en las canchas, reflejándose equidad de género en la práctica del ecuavóley ya que, en el $41,3 \%$ de polideportivos juegan damas y en el 58,7\% varones.

Palabras clave: Ecuavóley; masificación internacional; ecuavóley en el mundo; deportes con balón

\begin{abstract}
Migratory processes, as well as the unique characteristics of the ecuavolley, have allowed an accelerated massification within and outside of Ecuador, achieving a great socio-cultural impact. The objectives set were: determine the place and date of the first international ecuavolley championship, find out the countries in which ecuavolley is practiced, determine the number of people who meet daily to watch or practice this sport, determine if there is gender equality in your practice. In this research, a mixed methodology was developed, based on the qualitative paradigm, based on its four scientific phases, preparatory, field, documentary and informative analysis; quantitatively, the information obtained from 472 structured interviews was tabulated using the SPSS statistical program. Obtaining as a result: 13 countries in which ecuavolley is practiced, the first international ecuavolley championship was held in Madrid, Spain on April 29, 2007, with Saturday being the day with the highest influx on the fields, reflecting gender equity in the practice of ecuavolley since, in $41.3 \%$ of sports centers women play and in $58.7 \%$ men.
\end{abstract}

Key words: Ecuavolley; international massification; ecuavolley in the world; ball sports 


\section{RESUMO}

Os processos migratórios, assim como as características singulares da ecuavóley, permitiram uma massificação acelerada dentro e fora do Equador, com grande impacto sociocultural. Os objetivos propostos foram: determinar o local e a data do primeiro campeonato internacional de ecuavóley, conhecer os países em que o ecuavóley é praticado, determinar a quantidade de pessoas que se reúnem diariamente para assistir ou praticar este esporte, determinar se há igualdade de gênero em sua prática. Nesta pesquisa, desenvolveu-se uma metodologia mista, baseada no paradigma qualitativo, fundamentada em suas quatro fases científicas, preparatória, de campo, documental e informativa; quantitativamente, as informações obtidas em 472 entrevistas estruturadas foram tabuladas por meio do programa estatístico SPSS. Obtendo como resultado: 13 países em que o ecuavóley é praticado, o primeiro campeonato internacional de ecuavóley foi realizado em Madrid, Espanha, em 29 de abril de 2007, sendo o sábado o dia com maior afluxo de campos, refletindo a equidade de gênero em a prática do ecuavóley já que, em $41,3 \%$ dos centros esportivos as mulheres jogam e em $58,7 \%$ os homens.

Palavras-chave: Equavôlei, massificação internacional, ecuavóley no mundo, esportes com bola

\section{INTRODUCCIÓN}

El deporte transforma al juego en una actividad competitiva, con mayor número de reglas establecidas e institucionalizadas (Parlebás, 1993), los deportes se construyen en base selectiva de una tradición, siguiendo un ciclo histórico caracterizado por su creciente, internacionalización y masificación (Hernández y Carballo, 2002), de esta forma los marineros ingleses llevaron el fútbol a todo el mundo, estableciendo asociaciones en Europa y América (Suen, 2003); particularmente el ecuavóley está siendo masificado en diferentes partes del mundo por ecuatorianos, formando, clubes y asociaciones. Según (Galeano-Terán, 2020a). "Actualmente (...) el ecuavóley es uno de los deportes más practicados, superando el fútbol, ya que diariamente centenares de fanáticos y jugadores que practican el ecuavóley se dan cita en los principales polideportivos". (p. 81), los deportes con pelota que más practican los adolescentes ecuatorianos son el ecuavóley y el fútbol (Martínez, 2018), debido a su popularidad está incluido en el currículo de Educación Física ecuatoriano. (Galeano-Terán, 2018; 2020a).

En este orden de palabras resulta clave mencionar, que a pesar de la evolución e importancia que ha ganado el ecuavóley, actualmente no existe ningún estudio su práctica dentro y fuera del Ecuador, situación que limita futuros estudios sobre ese deporte. Es así que se decidió realizar un estudio sobre las principales canchas de ecuavóley a nivel mundial, mediante un muestreo intencional utilizando la herramienta digital formularios de Google para la recolección de datos.

Debido al impacto cultural y deportivo del ecuavóley, se vuelve trascendental conocer los países en los que se practica el ecuavóley, el número de personas que se dan cita diariamente a las canchas y determinar si existe equidad de género en su práctica, con la finalidad de brindar datos fehacientes que abran el camino a futuras investigaciones sobre este deporte y los deportes con balón practicados en Sudamérica.

En este sentido, es importante conocer la historia de los juegos con pelota y su evolución a través de los siglos, ya que la mayoría de actividades deportivas desde el principio de la humanidad, fueron concebidas como ejercicios para la supervivencia hasta que comenzaron a contener reglas, transformando el concepto y otorgándole variedad de interpretaciones, que han influenciado a la cultura de cada población hasta hoy en día (Sainz, 1992; Blanco, 2016).

La pelota maya o chaaj, se jugaba alrededor de 1400 años antes de Cristo en Mesoamérica, era practicada en un campo rectangular, cuyo 
objetivo era pasar la pelota por un anillo ubicado a una altura de unos tres metros y en el centro de un tablero de madera, presentando una inclinación haciendo ángulo agudo de entre 70 a 60 grados con el piso plano (Burgués, 2000; Cifuentes y Ramírez, 2019).

Otros deportes con pelota se desarrollaban en China, en el año 960 a. C. practicados por la dinastía Song, el juego alcanzó tal popularidad que en las grandes ciudades se organizaron clubes en los que sus miembros tenían que pagar cuotas de suscripción por jugar. Tenía dos modalidades de juego, una de ellas consistía en una especie de voleibol. (López, 2012).

Los juegos de pelota también eran conocidos en el antiguo Egipto, así como en Grecia, bajo la denominación de "aporraxis", actividad que consistía en botar la pelota con la mano. Los griegos jugaban a la "anacrousia", que era el juego del frontón. Otras evidencias de las prácticas de estos juegos romanos han quedado reflejadas en las iconografías de porcelanas con estelas funerarias de atletas, como es el caso de la Estela funeraria de un atleta de la primera mitad del siglo IV a.C. encontrada en El Pireo, Atenas (Museo Arqueológico Nacional de Atenas) (Gorris, 1981).

En el siglo XI después de Cristo, en España se jugaba un juego denominado "la pelota", siendo el deporte preferido para solemnizar las celebraciones religiosas, en lugares en los que una fiesta era menos atractiva cuando no había un desafío frente al frontón o frente a la pared que hacía sus veces, entre jugadores locales y pelotaris que acudían de otros pueblos, tierras o provincias no siempre limítrofes. Esto dependía de la resonancia que alcanzara la festividad o de la importancia del pueblo que la celebraba. (Jiménez, 2019), cada período crea su deporte reflejándose las características de cada pueblo, y la esencia de su población, tomando en cuenta el respeto y equilibrio entre la tradición y la renovación (Diem, 1966; Bringas, 2002).

\section{MÉTODO}

En el presente estudio se aplicó una metodología mixta, tomando en cuenta el enfoque cualitativo y su contribución con estrategias transversales en búsqueda $\mathrm{y}$ expansión de la información, a través de las fases preparatoria, trabajo de campo, analítica e informativa, dando la potestad al investigador en la toma de decisiones, cuando existen resultados similares entre enfoques. (Pérez Juste, 1985; Schwandt, Denzin y Lincoln, 1994; Atkinson, Coffey y Delamont, 1999; Gil, Rodríguez, y García, 1999; Pole y Lampard, 2002; Sánchez, 2020). Debido a la particularidad deportiva de esta investigación se mantuvo un proceso continuo en la toma de decisiones por parte de investigador, en base al análisis bibliográfico sobre las primeras actividades deportivas realizadas en otros países, permitiendo determinar la primera ciudad y país en la que se llevó a cabo un evento internacional de ecuavóley, posteriormente se aplicó entrevistas estructuradas a personas claves que conocían los países en los que se practica el ecuavóley actualmente, el número de personas que se dan cita diariamente a observar, o practicar este deporte y finalmente conocer si existe equidad de género en su práctica deportiva. (Deslauriers, 2004; Pitman y Maxwell, 1992; De Gialdino, 2006; Esparza, 2019). Las preguntas realizadas fueron: ¿En qué continente está ubicada la cancha de ecuavóley a la que usted asiste habitualmente?, ¿En qué país está ubicada esta cancha de ecuavóley?, ¿Qué días juegan ecuavóley?, ¿Juegan mujeres en la cancha que usted practica ecuavóley?, ¿Cuántas personas cree que asisten diariamente la cancha de ecuavóley? 
De esta manera pretendiendo medir intencionalmente con precisión las variables planteadas en el estudio (Arias, 2012; Rodríguez Jiménez y Pérez Jacinto, 2017; Hernández-Sampieri y Torres, 2018). Tomando en cuenta que este trabajo se fundamentó en base a herramientas del método cualitativo, contribuyendo con estrategias transversales fundamentada con un análisis documental en base a instrumentos empíricos, situándolo desde un enfoque descriptivo (Paz, 2003; Gialdino, 2006). Permitiendo la obtención de conclusiones confiables, aclaradas en base a la interpretación hermenéutica de datos, sobre el origen del ecuavóley, enmarcándonos dentro de un paradigma fenomenológico adecuado (Monly, 1980; Guba, 1989; Aróstegui, 1995; Duverger, 1996; Guba y Lincoln, 2002; Cabrera, 2005).

En lo referente a metodología cuantitativa, se tabuló los datos de las entrevistas estructuradas, que se aplicó a las personas que asistieron a las canchas de ecuavóley mediante el programa estadístico SPSS, permitiendo cumplir con los objetivos planteados. (Pita Fernández y Pértegas, 2002; Paitán, 2004; Pardo, Ruiz y San Martín, 2015).

Por ello, se empleó entrevistas estructuradas a un grupo focal de personas que practicaban o asistieron a las canchas de ecuavóley en Ecuador y varios países del mundo, a través de formularios de Google, obteniendo como resultado los países en los que se está practicando el ecuavóley, permitiendo la "interpretación" de datos, basada en lineamientos cualitativos, a partir de la realidad social, los valores, las costumbres, las ideologías y cosmovisiones, construida en base a un discursos subjetivos, ya que el investigador da sentido y significado particular a los resultados, tomando en cuenta que la investigación cualitativa permite analizar datos descriptivos, permitiendo revelar la verdadera historia; desarrollando conceptualizaciones que brindan la oportunidad de conocer e interpretar el pretérito, aportar con el presente y predecir el futuro. (Vilches, 1993; Del Valle Gastaminza, 1999; Galeano, 2003; Dulzaides Iglesias y Molina Gómez, 2004; Sánchez, 2006; Marzal, 2007; Peña Vera y Pirela Morillo, 2007; Torregrosa, 2010; Robles, 2011; Strauss y Corbin, 2016).

\section{RESULTADOS}

Se inició con un análisis documental para conocer la fecha, ciudad y país en la que se llevó a cabo el primer campeonato internacional de ecuavóley, según (Galeano, 2020b) afirma que el ecuavóley comenzó a practicarse a inicios del siglo XIX en las provincias de Imbabura y Loja evolucionando hasta llegar a ser el deporte más practicado por los ecuatorianos, dentro y fuera del Ecuador.

Posteriormente las fuentes bibliográficas consultadas arrojaron la fecha exacta en que se potenció la práctica del ecuavóley fuera de Ecuador, encontrando un reportaje del diario AS de España, en el que se evidencia la premiación de primer campeonato internacional de ecuavóley, como se puede apreciar en el figura 1. 


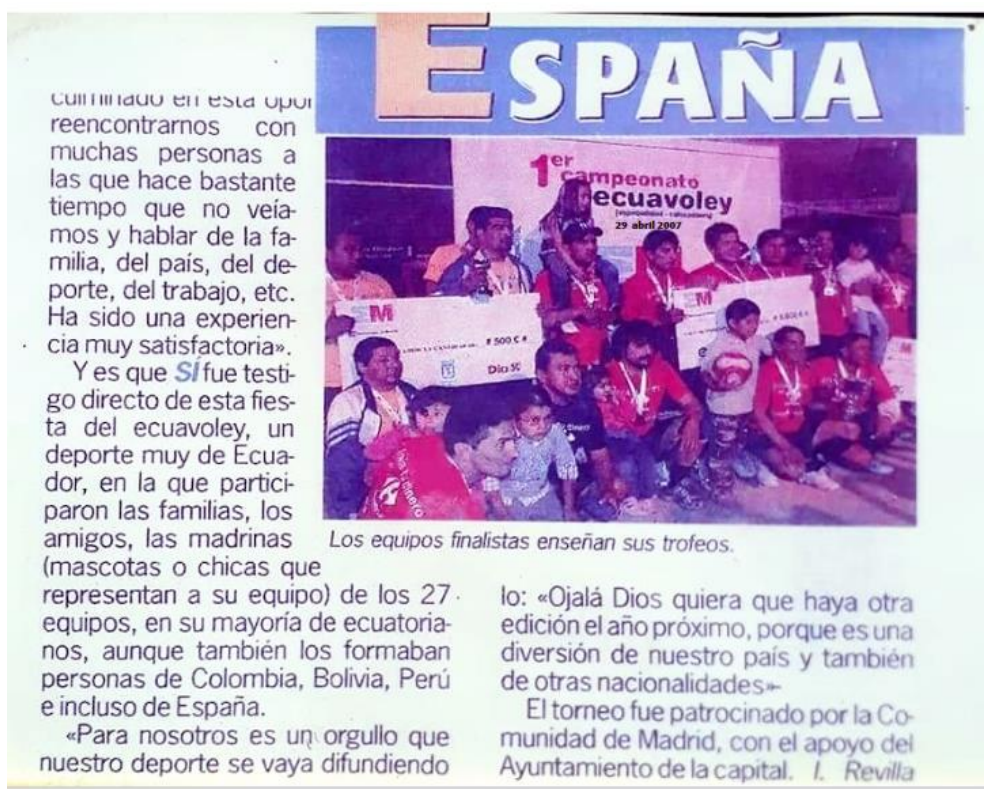

Figura 1. Madrid, España premiación del primer campeonato internacional de ecuavóley 29 de abril 2007. (Fuente Franklin García)

El artículo periodístico que se muestra en la Figura 1, brinda información fehaciente sobre el primer campeonato de ecuavóley, realizado en Europa en el año 2007 en el que participaron 27 equipos de distintos países, entre ellos Ecuador, Colombia, Bolivia, Perú, mismo que llamó la atención de periodistas españoles, ya que incluso se contó con un equipo representante de España, mencionando que fue una fiesta deportiva del ecuavóley, este evento también fue resaltado previo a su inauguración por el diario La Hora de Ecuador en su publicación del 17 de abril del 2007, cuyo encabezado manifestaba: "Localidad madrileña de Leganés acogerá 29 abril el I Campeonato de Ecuavoley", declarando que el evento deportivo estará patrocinado por la comunidad de Madrid, mientras que sus organizadores mencionaron que se convertirá en "una gran fiesta" y se espera la presencia de al menos 5000 seguidores. Acotando que la modalidad del campeonato será "colocadores".
Esta información contrasta con las fechas manifestadas en el libro elaborado por el Ministerio del Deporte Ecuatoriano en el año 2010, hoy Secretaría del Deporte, cuyo nombre es: "Ecuavoley Deporte Ecuatoriano por Tradición", en cuya página 68 , menciona que en el 2008 fue celebrado el primer campeonato internacional de ecuavóley, información que evidencia falta de compromiso con la historia del ecuavóley, y los primeros gestores de su práctica deportiva fuera del país, ya que se está desmereciendo el arduo trabajo realizado por los organizadores de los primeros eventos deportivos, que marcaron el inicio de la internacionalización del ecuavóley, además de manifestarse un clasismo erróneo en sus páginas al aducir que dentro de la "sociedad" quiteña se concibe al ecuavóley como un deporte practicado por taxistas y personal de la construcción ya que estos grupos juegan diariamente, palabras sin bases ni sustentos lógicos, peor científicos, ya que el ecuavóley 
es un deporte tradicional, practicado diariamente por un gran número de habitantes ecuatorianos, sin importar estratos económicos o sociales.

A continuación, se realizó un análisis estadístico cuantitativo de las entrevistas estructuradas realizadas a las personas que asisten a las principales canchas de ecuavóley, a las respuestas se asignaron valores numéricos para poder tabularlas en el programa estadístico SPSS.

Con la finalidad de conocer los países en los que se practica el ecuavóley actualmente, se realizaron las siguientes preguntas:

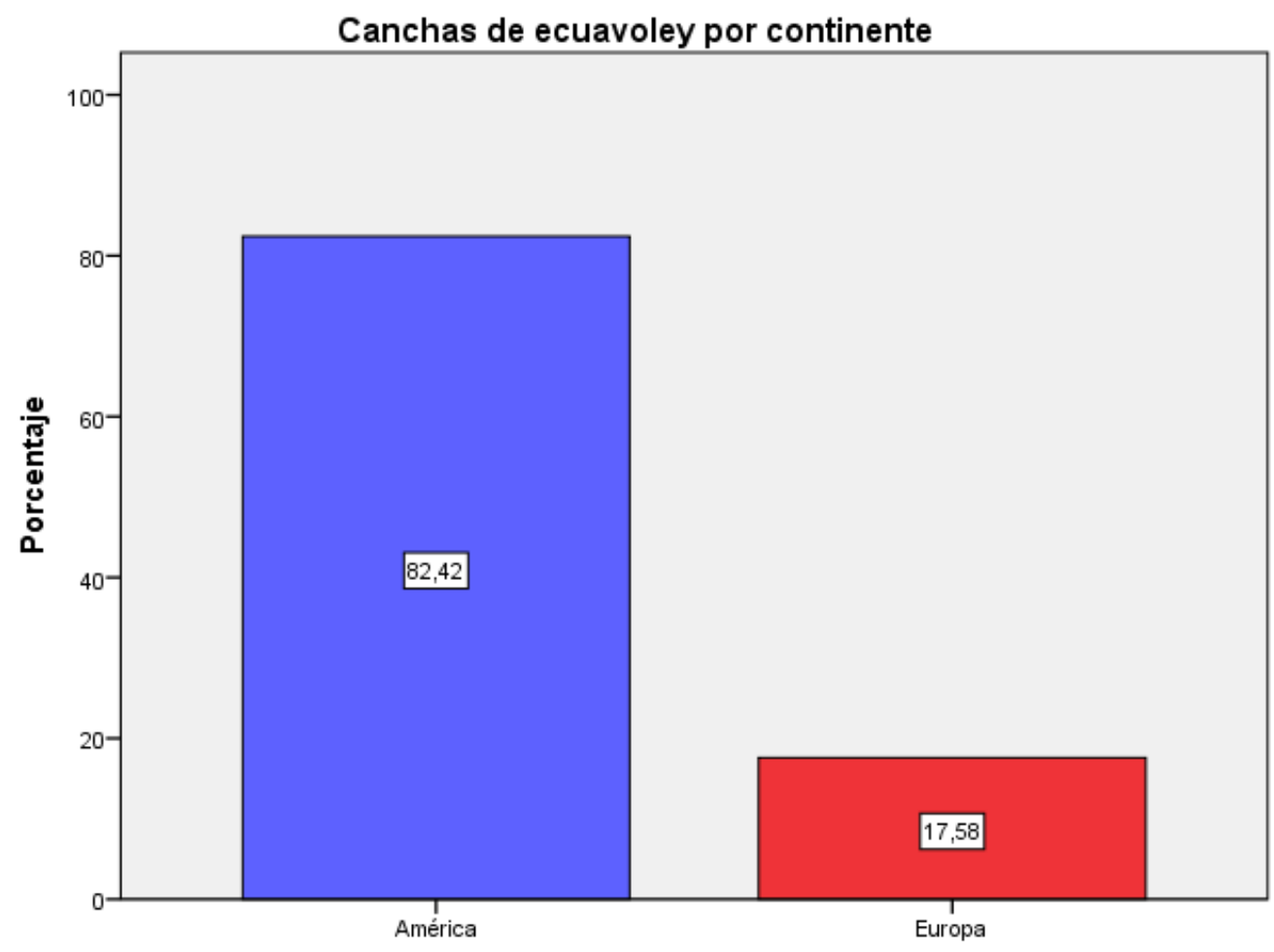

Gráfico 1. ¿En qué continente está ubicada la cancha de ecuavóley a la que usted asiste habitualmente?

Obteniendo como resultado que 389 canchas están ubicadas en el continente americano, mientras que 83 en el continente europeo (Gráfico 1), estos datos reflejan la internacionalización del ecuavóley después de los eventos deportivos realizados en el 2007 en España. 


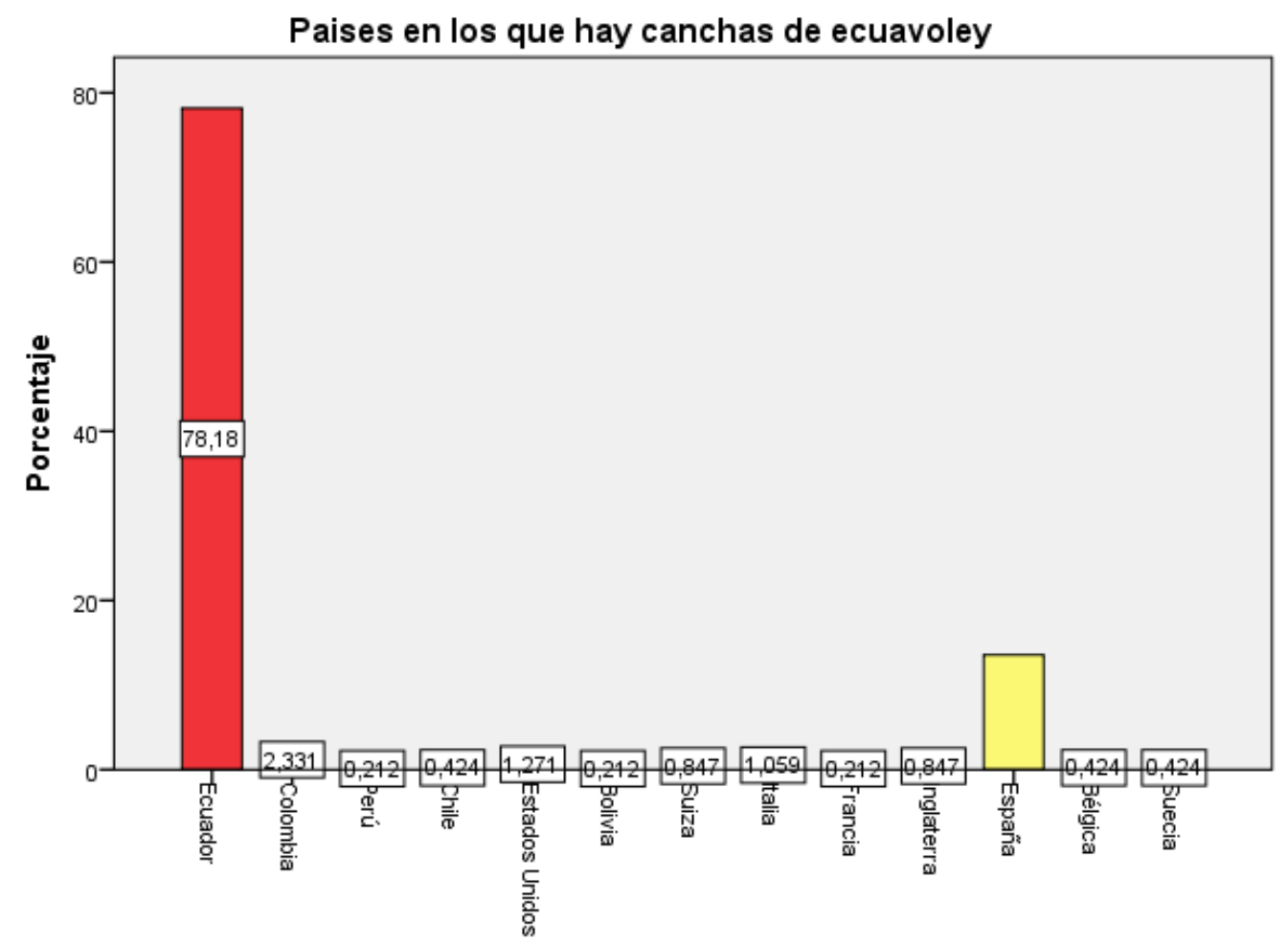

Gráfico 2. ¿En qué país está ubicada la cancha de ecuavóley?

Se pudo determinar en el gráfico 2 del estudio, después de la aplicación de las entrevistas que: 369 canchas están ubicadas en Ecuador 64, España 11, Colombia 6, Estados Unidos 5, en Italia 4, en Suiza 4, Inglaterra 2, Suecia 2, Bélgica 2, Chile, Perú, Bolivia, y Francia cuentan con una cancha cada uno, siendo 13 en total los países en los que se juegan ecuavóley en la actualidad, evidenciando un aumento significativo de países en los que se juegan ecuavóley, tomando como referencia el primer campeonato internacional de ecuavóley en el que participaron cinco países. 


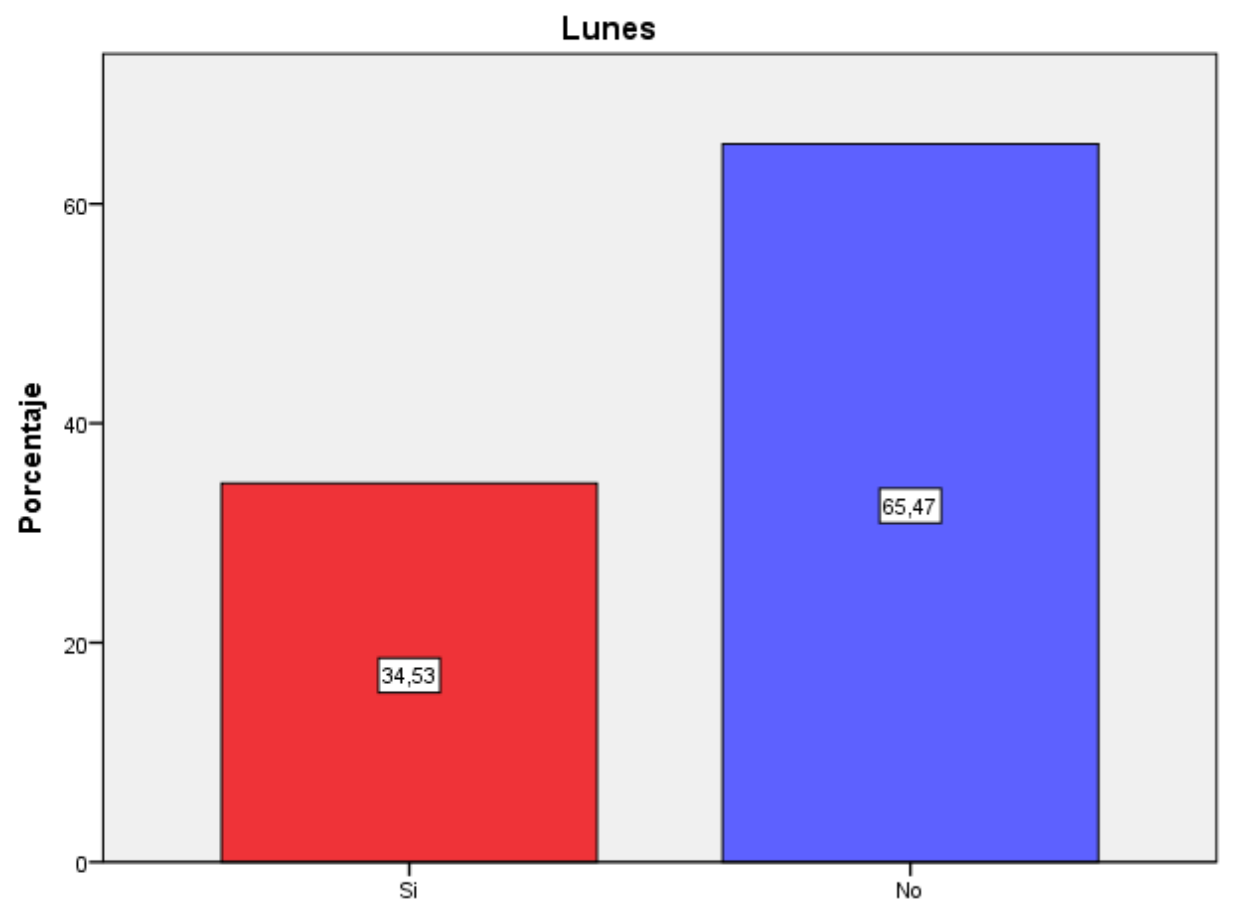

Gráfico 3. ¿Qué días juegan en la cancha de ecuavóley a la que usted asiste?

El resultado de esta pregunta reflejó, que el día lunes juegan en 163 canchas mientras que en 309 polideportivos no lo hacen (Gráfico 3). Observándose que en el 34,53\% de canchas prefieren jugar desde el primer día laboral de la semana. 


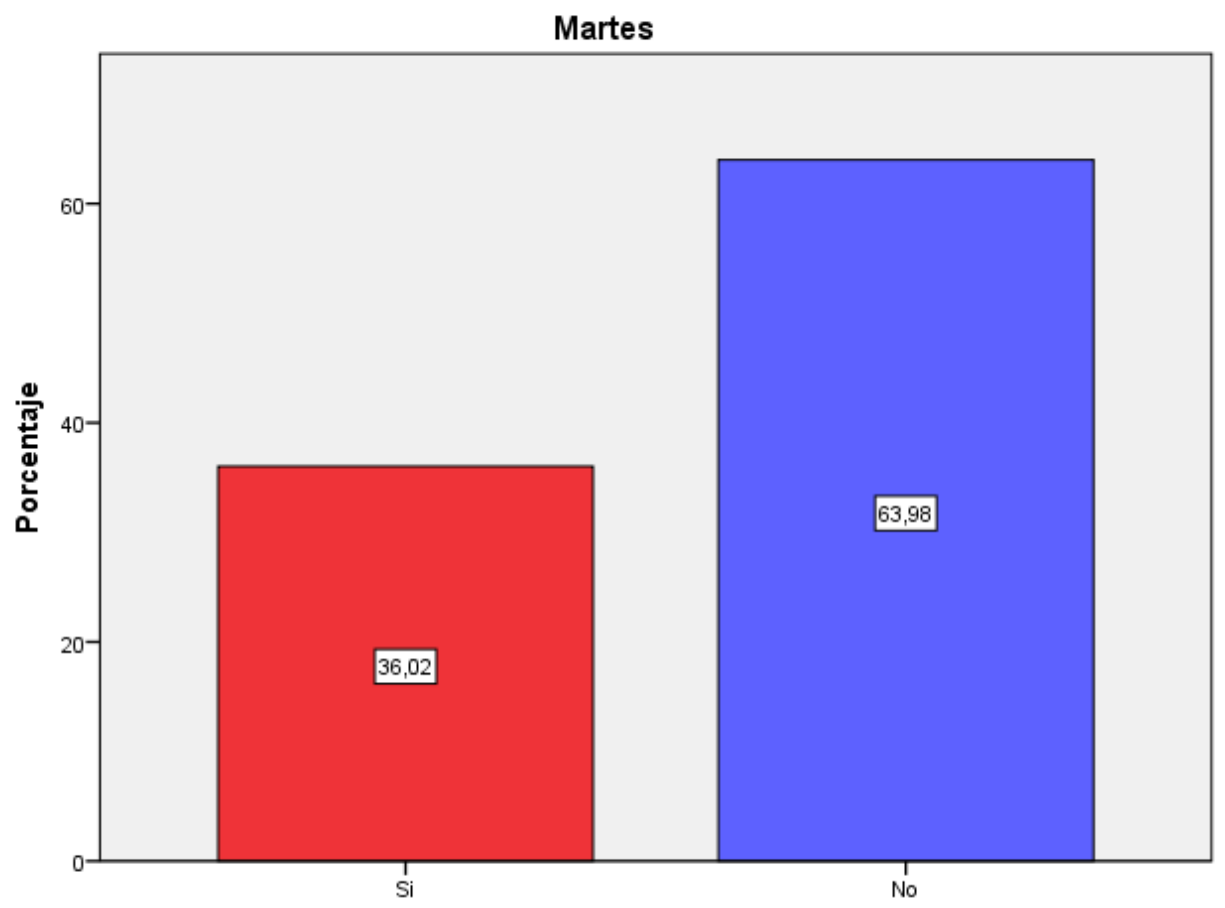

Gráfico 4. Análisis por día martes

Por otro lado, el día martes aumenta ligeramente el número de canchas en las que practican ecuavóley siendo 170, mientras que en 302 polideportivos no lo hacen. (Gráfico 4).

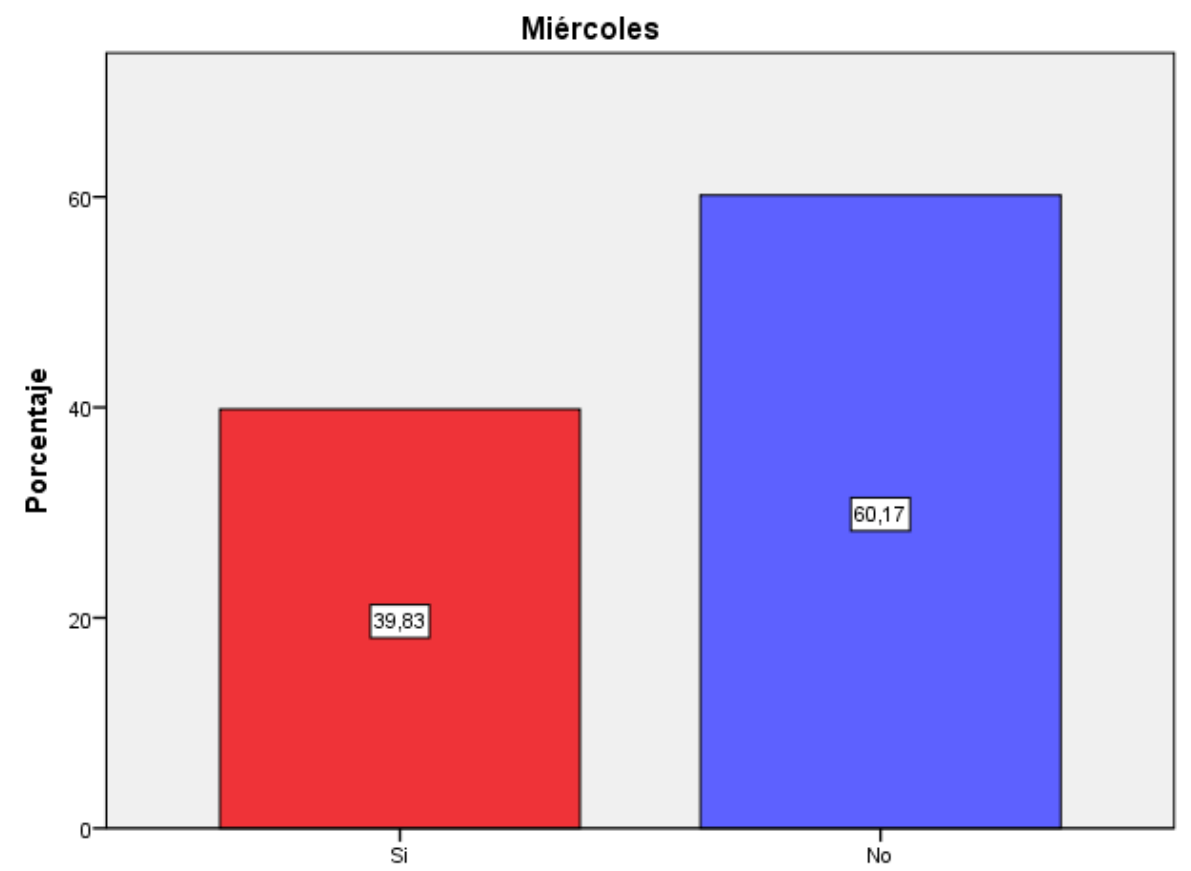

Gráfico 5. Análisis por día miércoles 
Por su parte en el día miércoles practican ecuavóley en 188 polideportivos, descansando en 284 canchas, aumentando ligeramente el número de polideportivos en relación al día martes, (Gráfico 5).

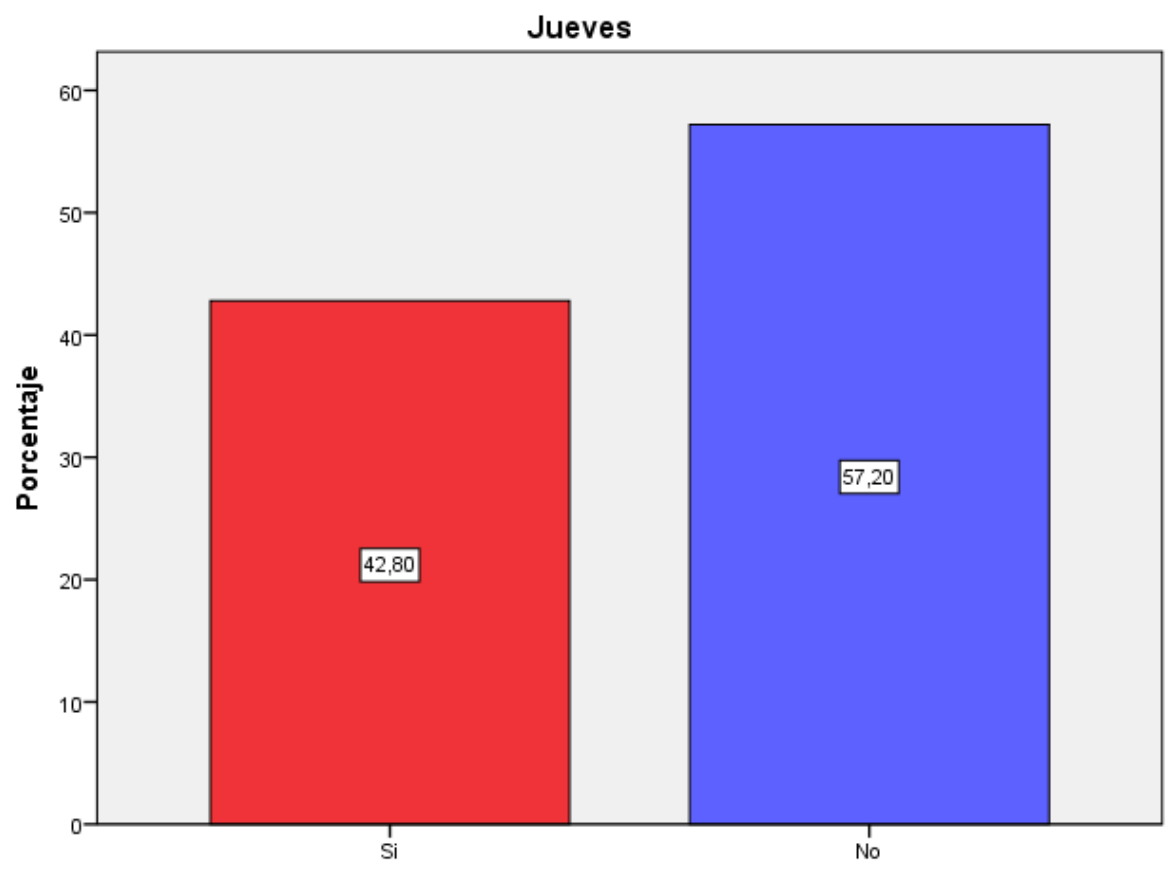

Gráfico 6. Análisis por día jueves.

Particularmente el día jueves practican ecuavóley en 202 canchas, mientras que en 270 no lo hacen, Siendo un equivalente al 42,8\% de polideportivos en los que juegan ecuavóley. (Gráfico 6).

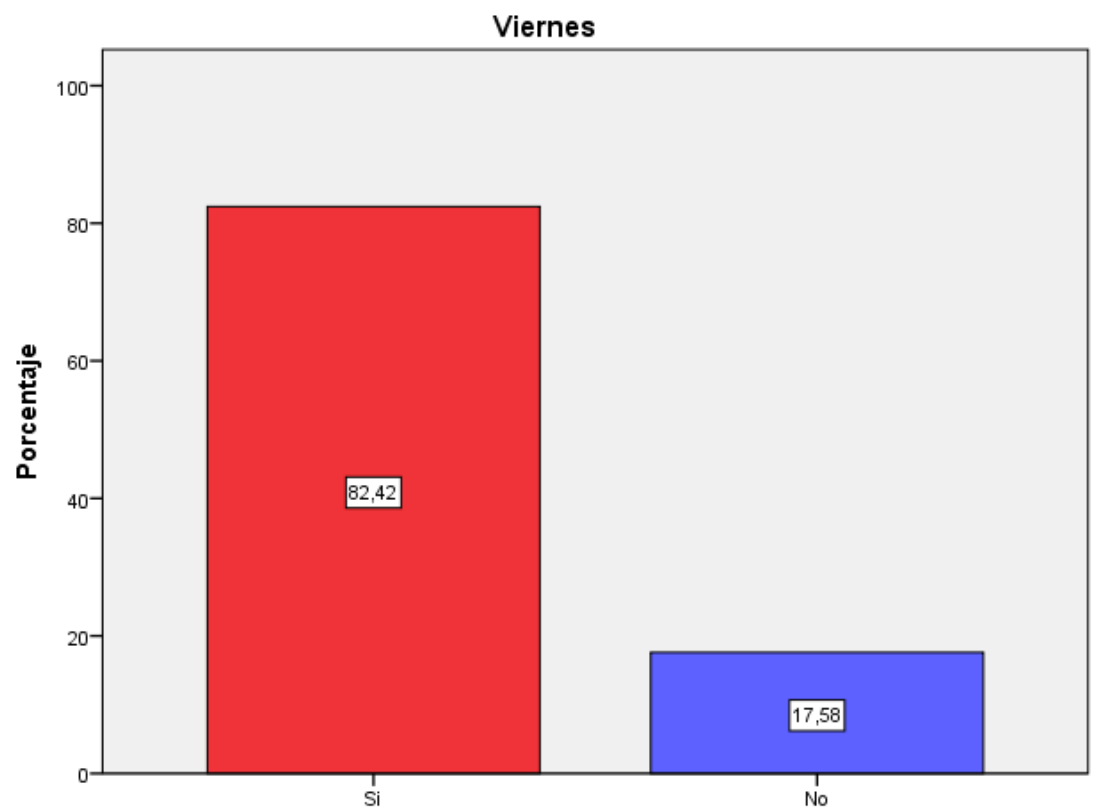

Gráfico 7. Análisis por día viernes 
El día viernes muestra una varianza ya que en 389 canchas practican ecuavóley, mientras en 83 polideportivos no lo hacen. Mostrando que el 82,42\% de polideportivos tienen afluencia de fanáticos y deportistas, (Gráfico 7).

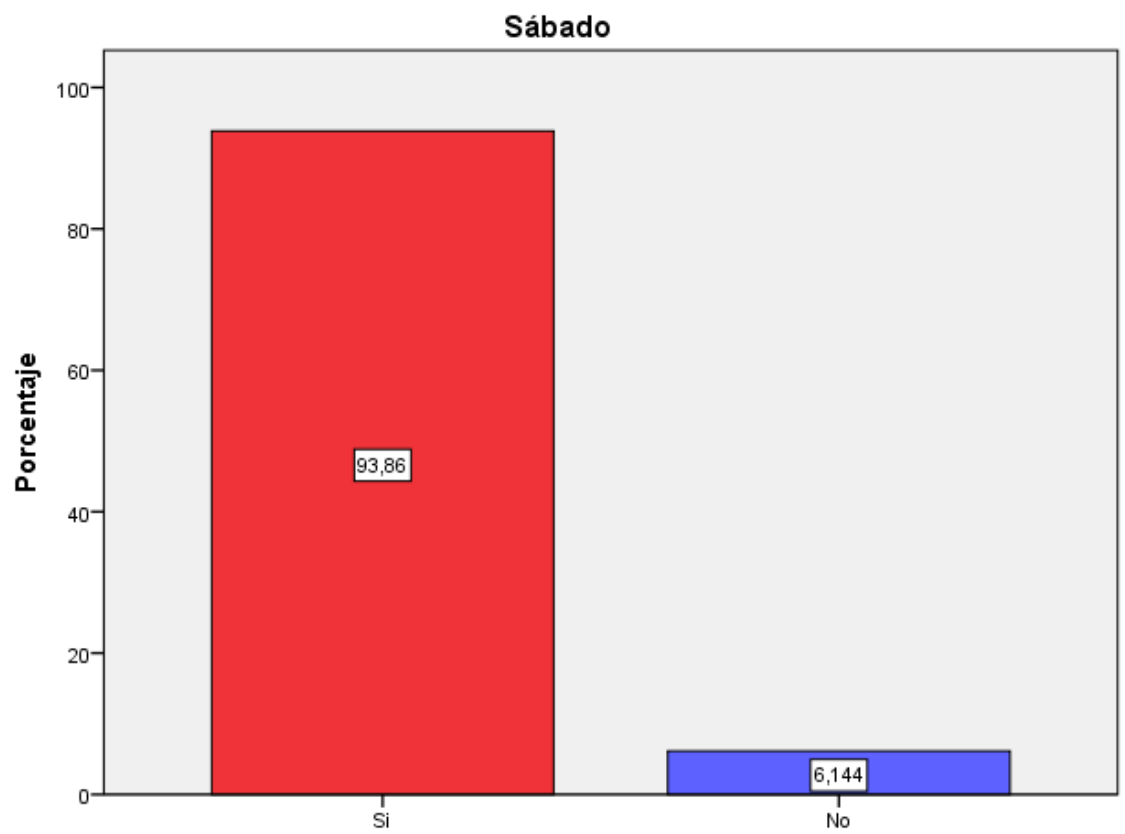

Gráfico 8. Análisis por día sábado

En el gráfico 8 hay que destacar que el sábado es el día que más practican ecuavóley, llegando a un total de 443 polideportivos, equivalente al 93,86\% de canchas, mientras que $29 \%$ descansan, evidenciándose una marcada diferencia.

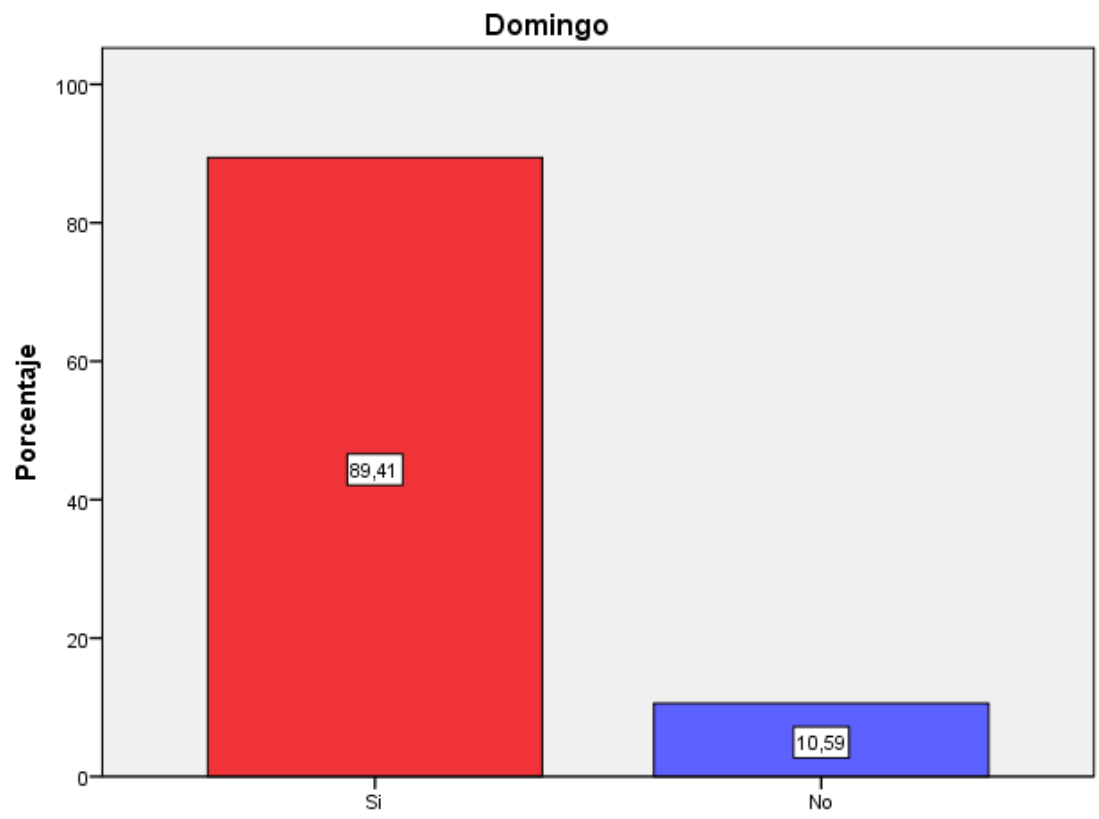

Gráfico 9. Análisis por día domingo. 
Finalmente, el domingo (Gráfico 9) es el segundo día que más practican con 422 canchas activas, equivalente a 89,41\%, contrastando con 50 polideportivos inactivos. Notándose que el ecuavóley es practicado de lunes a domingo en los diferentes complejos.
Posteriormente, se analizó las respuestas de la pregunta elaborada con el objetivo de conocer o determinar si existe equidad de género en la práctica del ecuavóley, y si hay una marcada diferencia o su práctica es equitativa, por ello se preguntó:

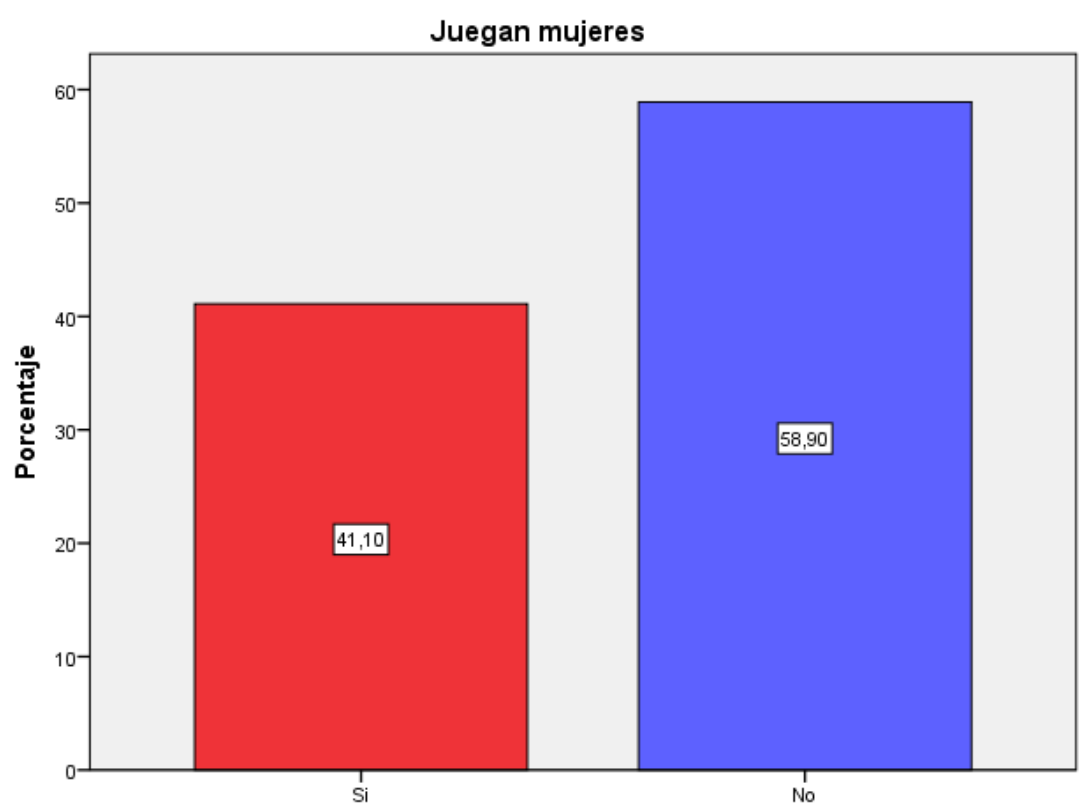

Gráfico 10. ¿En la cancha de ecuavóley a la que usted asiste juegan mujeres?

Observándose importantes resultados ya que, en 194 complejos deportivos, equivalente al $41,10 \%$ juega activamente mujeres, mientras que en 278 no lo hacen, evidenciándose que el ecuavóley es un deporte que permite la práctica activa y equitativa de hombres y mujeres. (Gráfico 10).

Finalmente, para dar respuesta a la última variable se preguntó: 


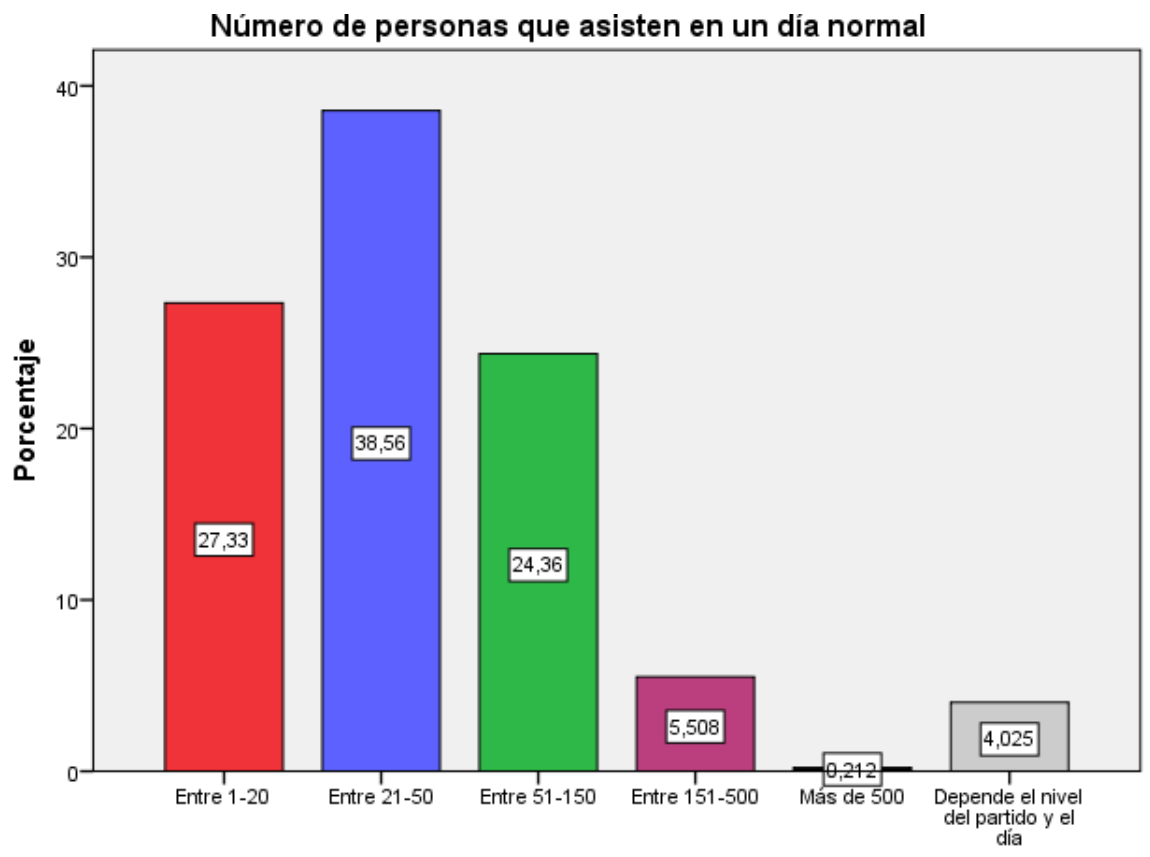

Gráfico 11. ¿Cuántas personas cree usted que se dan cita diariamente en la cancha de ecuavóley?

En 129 canchas respondieron que varían entre 1 y 20 , en 182 entre 21-50, en 115 entre 51-150, en 26 entre 151-500, en una cancha más de 500, y en 19 polideportivos manifestaron que dependía del nivel de jugadores y el día (Gráfico 11).

Del análisis de las preguntas anteriores se manifestó que el ecuavóley actualmente es practicado en el continente europeo evidenciándose el $17,6 \%$ de canchas de ecuavóley, superado por América con el 82,4\%. Los países en los cuales existe registros de polideportivos de ecuavóley son: Ecuador, Colombia, Perú, Chile, Estados Unidos, Bolivia, Suiza, Italia, Francia, Inglaterra, España, Bélgica, Suecia, sumando un total de 13 naciones, resulta oportuno mencionar que el número de países podrá duplicarse, pero debido a leyes extranjeras han preferido no brindar información de la ubicación de las canchas, en este trabajo de investigación se obtuvo un total de 412 registros.

El porcentaje aproximado de asistencia diaria en las canchas de ecuavóley fue manifestado con los siguientes resultados $27,3 \%$ entre $1-20$ personas; $38,6 \%$ entre $21-50$ personas; $24,4 \%$ entre $51-150$ personas; $5,5 \%$ entre $151-500$ personas; $2 \%$ más de 500 personas; $4 \%$ dependiendo el nivel del partido y el día.

Finalmente se evidenció equidad de género en la práctica del ecuavóley, según el resultado del presente estudio el $41.1 \%$ equivalente a 194 polideportivos manifiestan que, las damas juegan diariamente en sus instalaciones.

Finalmente, el sábado es el día que más personas asisten a las canchas de ecuavóley a observar los partidos reflejándose con el 93,9\%.

Como se puede observar el ecuavóley es practicado en muchos países a nivel mundial, siendo embajador de la cultura ecuatoriana y latinoamericana, aportando con la historia, a nivel mundial los deportes tradicionales cada día toman mayor importancia, representando una excelente herramienta de aprendizaje para la población, ya que se refleja la idiosincrasia cultural de cada pueblo o nación. 
(Parra y Sancho, 2008; Lara y Cachón, 2010; Robles, 2010; Méndez-Giménez y FernándezRío 2011; Galeano-Terán, 2020a; GaleanoTerán, 2020b; Robles y Robles, 2020).

\section{Discusión}

El presente estudio permitió además de conocer los países en los que juegan ecuavóley actualmente, determinar la fecha del primer campeonato internacional de ecuavóley, contrastando con las afirmaciones del libro elaborado por el Ministerio del Deporte Ecuatoriano en el año 2010, hoy Secretaría del Deporte, texto que debería ser analizado y puesto a revisión por pares, ya que aparte de brindar información equivocada sobre la internacionalización del ecuavóley, muestra en algunas de sus páginas un marcado clasismo social, aspectos que pueden perjudicar a la verdadera historia y evolución del ecuavóley.

También hay que mencionar que a pesar de la gran cantidad de personas que practican ecuavóley, actualmente existe en repositorios académicos un número reducido de investigaciones sobre su historia y masificación, siendo un limitante para comparar y discutir con otros estudios sobre ecuavóley (GaleanoTerán, 2020a), limitaciones científicas que dan importancia a este artículo ya que es el primer trabajo realizado dentro y fuera de Ecuador, siendo una importante base científica para futuros estudios sobre ecuavóley y su impacto a nivel mundial. Resulta oportuno mencionar que actualmente en la mayoría de países el ecuavóley es practicado por ecuatorianos que residen en el extranjero, pero debido a sus características de juego cada día se visualiza un mayor número de personas de otros países observando o practicando este deporte.
Finalmente se puede mencionar que, debido al poco interés de las autoridades ecuatorianas, el ecuavóley no es un deporte reglado en su totalidad, situación que da paso a falsas asociaciones $\mathrm{y}$ federaciones que no son reconocidas por ningún organismo deportivo oficial o Federación en Ecuador, ya que no existe una base legal aprobada por el organismo rector del Deporte Ecuatoriano.

\section{CONCLUSIONES}

El primer campeonato internacional de ecuavóley se desarrolló Madrid, España el 29 de abril del 2007, marcando un importante inicio sobre la masificación de este deporte fuera del Ecuador, a este importante evento se dieron cita representantes de cinco países, Colombia, Bolivia, Perú, Ecuador y España, permitiendo conocer la verdad de los hechos, ya que el Ministerio del Deporte de Ecuador, hoy Secretaría del Deporte manifestó erróneamente en su texto: "Ecuavoley Deporte Ecuatoriano por Tradición”, que el primer campeonato internacional se celebró en 2008 en Italia.

Dentro del presente estudio, también se pudo recoger información de 472 canchas de ecuavóley, ubicadas de mayor a menor número de polideportivos en el siguiente orden, Ecuador, Colombia, Perú, Chile, Estados Unidos, Bolivia, Suiza, Italia, Francia, Inglaterra, España, Bélgica, Suecia, sumando un total de 13 naciones, en las que se practica ecuavóley de forma masiva actualmente, el número podría aumentar debido al proceso migratorio, intercambios deportivos $y$ educativos. Es importante mencionar que es una pequeña muestra del total de canchas que existen actualmente, dentro y fuera del país. 
También se obtuvieron datos importantes en la equidad de género en la práctica de ecuavóley en los 13 países estudiados, ya que en 194 canchas juegan activamente damas, aspecto importante a considerar con la finalidad de masificar el ecuavóley dentro y fuera del Ecuador.

A pesar que los días de mayor práctica del ecuavóley son sábados y domingos se observa un alto número de canchas que realizan la actividad deportiva de lunes a viernes, de esta manera permitiendo alcanzar los objetivos planteados.

El ecuavóley es un deporte tradicional que representa cultura y tradición ecuatoriana en todas partes del mundo en las que se practique el deporte, por este motivo debe conservar su esencia reflejada desde su nombre creado y utilizado a partir de 1950, en este sentido se vuelve fundamental evitar bilingüismos 0 cambios de nombre, aspecto que alterarían el origen y etimología del vocablo ecuavóley, deporte con 120 años de historia.

\section{REFERENCIAS}

Aróstegui, J. (1995). La investigación histórica: teoría y método. Historia Contemporánea, (13-14)

Atkinson, P., Coffey, A., y Delamont, S. (1999). Ethnography: Post, Past, and Present. Journal of Contemporary Ethnography, 28(5), 460-471. https://doi.org/10.1177/0891241990280 05004

Blanco, R. (2016). Actividad física y deporte a lo largo de la historia: orígenes, motivación, causas, motivaciones y relación con el ámbito educativo. Tesis de grado, universidad de la Rioja. http://www.unirioja.es

Bringas, M. (2002). Una aportación a la evolución de la pelota vasca en el ámbito de la estrategia, táctica y técnica: mano individual, en trinquete vs. En frontón de pared izquierda. (Tesis Doctoral). Universidad del País Vasco, España. http://dialnet.unirioja.es/servlet/tesis?cod igo $=212479$

Burgués, P. L. (2000). Juegos y deportes populares tradicionales (Vol. 567). Publicaciones Inde.

Cabrera, F. C. (2005). Categorización y triangulación como procesos de validación del conocimiento en investigación cualitativa. Teoría, 14(1), 61-71. http://www.redalyc.org/pdf/299/299001 07.pdf

Cifuentes, J. F. P., y Ramírez, S. P. (2019). Los ancestrales deportes de pelota maya en el contexto educativo de Guatemala. Revista Latinoamericana de Educación y Estudios Interculturales-RLEEI ISSN: 2448-8801, 3(4), 119-134. Comunicación, España

Del Valle Gastaminza, F. (1999). El análisis documental de la fotografía. Cuadernos de documentación multimedia, Revista Espacios, (8), 26. http://www.revista espacios.com/cited2017/cited201717.html

Deslauriers, J. P. (2004). Investigación cualitativa: guía práctica. Editorial Papiro

Diem, C. (1966). Historia de los deportes: Volumen I. Luis de Caralt.

Dulzaides Iglesias, M. E., y Molina Gómez, A. M. (2004). Análisis documental y de información: dos componentes de un mismo proceso. Acimed, 12(2), 1-1. http://scielo.sld.cu/scielo.php?script=sci_a rttext\&pid=S1024-94352004000200011

Duverger, M. (1996.). Métodos de las ciencias sociales/por Maurice Duverger Gijón: Trea. España

Esparza, D. (2019). Historia y deporte: la necesidad de investigar génesis de deportes concretos. [History and Sport: The necessity of studying the genesis of sports]. RICYDE. Revista Internacional de Ciencias del Deporte. Doi: 10.5232/ricyde, 15(56), 119-122. http://doi.org/10.5232/ ricyde2019.056ed

Galeano, M. E. (2003). Diseño de proyectos en la investigación cualitativa. Universidad Eafit.

Galeano-Terán, A. (2020a). Ecuavóley origen e historia en la provincia de Imbabura. Recinatur International Journal of Applied Sciences, Nature and Tourism, 2(1), 81-97. 
http://revistasojs.utn.edu.ec/index.php/re cinatur/article/view/410/313

Galeano-Terán, A. (2020b). Historia del ecuavóley: evolución cultural. Horizontes. Revista De Investigación En Ciencias De La Educación, 4(15), $309 \quad$ - 325. https://doi.org/10.33996/revistahorizont es.v4i15.118

Galeano-Terán, A. S. (2018). Diseño instruccional de actividades deportivas complementarias en el currículo de educación física para la formación integral del estudiante (Tesis de Maestría). http://repositorio.utn.edu.ec/handle/1234 $56789 / 7827$

Gialdino, V. (2006). Estrategias de investigación cualitativa. Barcelona: Gedisa, 42-50.

Gil, J., Rodríguez, G., y García, E. (1999). Metodología de la investigación cualitativa. Málaga: aljibe. http://catedranaranja. com.ar/taller5/notas_T5/metodologia_inv estig_cap.3.pdf

Gorris, J.M. (1981). El juego y el juguete. Queimada, España

Guba, E. G. (1989). Criterios de credibilidad en la investigación naturalista. La enseñanza: su teoría y su práctica. Akal.148-165

Guba, E., y Lincoln, Y. (2002). Paradigmas en competencia en la investigación cualitativa. Por los rincones. Antología de métodos cualitativos en la investigación social. Sonora. 113-145

Hernández, N. F., y Carballo, C. G. (2002). Acerca del concepto de deporte: Alcances de su (s) significado (s). Educación Física y Ciencia, 6, 87-102. http://www.madrimasd.org/revista/revist a31/tribuna/tribuna2.asp

https://dialnet.unirioja.es/servlet/articulo ?codigo $=6220913$

Jiménez, E. (2019). Retrospectiva histórica del juego y deporte tradicional a través de la cultura segoviana. Historia de la Educación, 38, 127-154. http//dx.doi.org/10.14201/ hedu201938127154

Lara, A. J., y Cachón, J. (2010). Kinball: los deportes alternativos en la formación del/la docente de educación física. Congrés
Internacional de Ditáctiques, España http://dugidoc.udg.edu/bitstream/handle /10256/3001/491.pdf?sequence $=1$

Localidad madrileña de Leganés acogerá 29 abril el I Campeonato de Ecuavóley. (17 de abril del 2007). La Hora, p.1. http://lahora.com.ec/noticia/559285/loca lidad-madrilec3b1a-de-leganc3a9sacogerc3a1-29-abril-el-i-campeonato-deecuavoley

López, A. J. M. (2012). Introducción a la historia de los deportes en la China Antigua= Introduction to the history of sports in the Ancient China. Materiales para la Historia del Deporte, (10), 105-116. http://dialnet.unirioja.es/servlet/articulo? codigo $=4094564$

Martínez Benítez, J. E. (2018). Diferenciales de Género y Actividad Física en los estudiantes de la Universidad Central del Ecuador. Universidad de Alicante (tesis doctoral).

http://hdl.handle.net/10045/999

Marzal, J. M. (2007). Cómo se lee una fotografía: interpretaciones de la mirada. Ediciones Cátedra, España

Méndez-Giménez, A., y Fernández-Río, J. (2011). Análisis y modificación de los juegos y deportes tradicionales para su adecuada aplicación en el ámbito educativo. Retos. Nuevas tendencias en Educación Física, Deporte y Recreación, (19), 54-58. http://www.redalyc.org/pdf /3457/345732285011.pdf

Ministerio de Deporte del Ecuador. (2010). Ecuavóley deporte ecuatoriano por tradición. Editorial Markapasos, Ecuador

Parlebás, P. (1993). Problemas del juego en la Educación Física. In La Plata, en Actas Primer Congreso Argentino de Educación Física y Ciencias. Departamento de Educación Física, Universidad la Plata, Argentina

Parra, C., y Sancho, M. (2008). Deportes alternativos: una propuesta práctica desde el punto de vista del profesor. In $V$ congreso nacional y III congreso iberoamericano de deporte en edad escolar: "Nuevas Tendencias y perspectivas de futuro, España, 351-374 
Paz, M. (2003). Investigación cualitativa en educación. Fundamentos y tradiciones. Editorial Mcgraw Hill. México

Peña Vera, T., y Pirela Morillo, J. (2007). La complejidad del análisis documental. Información, cultura y sociedad, (16), 5581. http://eprints.rclis.org/17138/

Robles, J. (2010). Motivos que llevan a los profesores de Educación Física a elegir los contenidos deportivos en la E.S.O. Retos. Nuevas tendencias en Educación Física, Deporte y Recreación, 18, 5-8

Robles, A., y Robles, J. (2020). La participación en las clases de educación física la ESO y Bachillerato. Un estudio sobre un deporte tradicional (Balonmano) y un deporte alternativo (Tchoukball). (Physical education involvement in middle and high School. Comparison between a traditional. Retos, (39), 78-83. http://doi.org/ $10.47197 /$ retos.v0i39.78129

Robles, B. (2011). La entrevista en profundidad: una técnica útil dentro del campo antropofísico. Cuicuilco, 18(52), 3949. http://www.scielo.org.mx/scielo.php?
script=sci_arttext\&pid=S0185-16592011 000300004

Sainz, M. (1992). Historia de la educación física. Cuadernos de sección. Educación, 5, Donostia. 27-47. http://d1wqtxts1xzle7. cloudfront.net

Sánchez, J. M. (2006). El documento fotográfico. Historia, usos, aplicaciones

Sánchez, R. (2020). Antropología del deporte: lineamientos teóricos. Editorial: Consejo Superior de Investigaciones Científicas, España

Schwandt, T. A., Denzin, N. K., y Lincoln, Y. S. (1994). Handbook of qualitative research, Ed: Denzin y Lincoln. Inglaterra

Suen, A. (2003). La historia del fútbol (The Story of Soccer). The Rosen Publishing Group, Estados Unidos

Torregrosa, J. F. (2010). Modelos para el análisis documental de la fotografía. Documentación de las Ciencias de la Información, 33, 329-342

Vilches, L. (1993). La lectura de la imagen. Prensa, cine, televisión. Paidó 